\title{
In vivo neural isolation of the canine jejunoileum: temporal adaptation of enteric neuropeptides
}

\author{
D K Nelson, M G Sarr, V L W Go
}

\begin{abstract}
This study was designed to assess temporal changes in concentrations of neuromodulatory peptides in plasma and gastrointestinal tissues after in vivo neural isolation of the entire canine jejunoileum. Fasting plasma and transmural biopsy specimens of stomach, duodenum, jejunum, ileum, and colon were obtained from the same dogs before and two, six, and 12 weeks after in situ neural isolation of the entire jejunoileum. Concentrations of vasoactive intestinal peptide, substance $P$, and neuropeptide $Y$ were determined by quantitative radioimmunoassay. Tissue concentrations of vasoactive intestinal peptide and substance $P$ in the neurally isolated regions increased progressively with time $(198 \%$ and $217 \%$ average maximal increases, respectively), while fasting plasma concentrations changed little. Neuropeptide Y concentrations in plasma and in the jejunoileum were decreased (by $30 \%$ to $70 \%$ ) at two weeks and remained decreased thereafter. Temporal changes in tissue neuropeptide concentrations occur in the neurally isolated jejunum and ileum. These adaptive changes in the neuropeptidergic innervation of the gut may play a role in the alterations in enteric function that occur after extrinsic denervation and after intestinal transplantation.
\end{abstract}

The gastrointestinal tract is innervated by an extensive network of intrinsic and extrinsic peptide containing neurons. Neuropeptides, including vasoactive intestinal peptide, substance $P$, and neuropeptide $Y$, coexist with and modulate the action of classic neurotransmitters such as norepinephrine and acetylcholine, ${ }^{1-3}$ thereby impacting directly and indirectly on blood flow, smooth muscle contractility, secretion, absorption, gastrointestinal transit, and pancreatic function. ${ }^{+6}$ Changes in the content or release of these neuromodulatory agents in response to the denervation necessitated by various surgical procedures or by intestinal transplantation may have local and distant effects on gastrointestinal function.

We have developed an in vivo canine model of the in situ neurally isolated small bowel that has allowed us to study several aspects of gut function after disruption of all neural continuity to the entire jejunoileum. ${ }^{78} \mathrm{An}$ advantage of this model, in contrast with a true transplantation model, is that it avoids the potentially confounding effects of immune rejection, immunosuppressive drugs, and harvest ischaemia, all of which may have profound effects on intestinal function. In this way the effects of intrinsic and extrinsic neural disruption can be examined selectively. This study was designed to assess changes in concentrations of selected neuropeptides in gut tissues and in plasma after neural isolation. Moreover, we were interested in how any alterations in neuropeptide concentrations that occurred might change over time as a function of local adaptation to the denervation.

\section{Methods}

Surgical procedures, subsequent care of animals, and the conduct of experiments were performed after approval from and according to criteria set forth by the Institutional Animal Care and Use Committee of the Mayo Foundation, in accordance with the guidelines of the National Institutes of Health and Public Health Service policy on the humane use and care of laboratory animals.

PREPARATION OF ANIMALS AND PROCUREMENT OF BIOPSY SPECIMENS

Six female mongrel dogs weighing 15 to $18 \mathrm{~kg}$ were anaesthetised with thiopental sodium (25 $\mathrm{mg} / \mathrm{kg}$ iv) and maintained with inhaled halothane (Ayerset Laboratories, New York, NY). After a 12 hour fast, plasma was obtained for baseline peptide assays before the animals were anesthetised. A midline celiotomy was performed and transmural biopsy specimens (approximate area $=1.0 \mathrm{~cm}^{2}$ ) were taken from the proximal gastric corpus, antrum, mid-duodenum, proximal and distal one third of jejunum, proximal and distal one third of ileum, mid-proximal colon, and mid-distal colon (Fig 1A). Biopsy specimens were taken from the antimesenteric surface of the intestine and never included $>30 \%$ of the circumference in an attempt to minimise disruption of enteric continuity. Biopsy sites were oversewn transversely to avoid intestinal narrowing. These initial biopsy specimens served as the baseline control specimens from neurally intact bowel.

All dogs then underwent in situ neural isolation of the entire jejunoileum, as described previously $^{8}$ and depicted in Figure 1B. In brief, the superior mesenteric artery and vein were isolated immediately distal to the inferior pancreatoduodenal vessels. From this point, both of the mesenteries up to the walls of the distal duodenum and distal ileum were completely transected in radial fashion and all neural, lymphatic, and connective tissues accompanying the superior mesenteric vessels were transected and ligated. The superior mesenteric artery and vein were then meticulously stripped of investing adventitia for $2 \mathrm{~cm}$ using optical magnification. These procedures extrinsically denervated the entire jejunoileum. Completion of the model of neural isolation was accomplished by transecting 


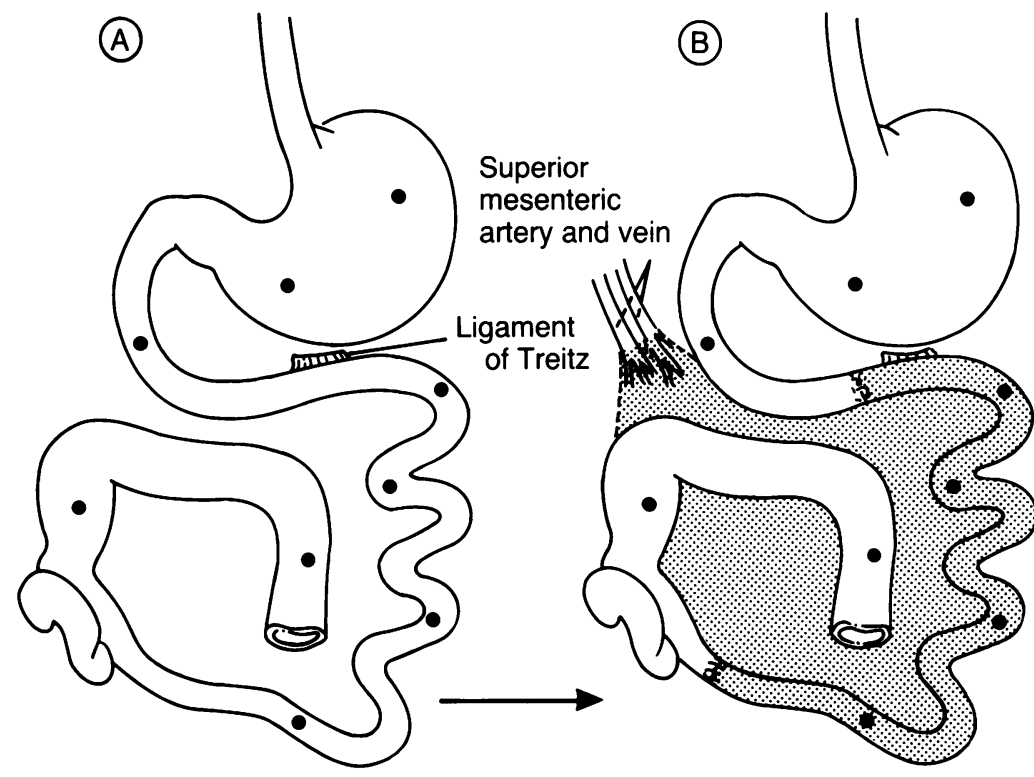

Figure 1: Preparation of canine model. (A) Transmural biopsy specimens were taken from neurally intact bowel at sites indicated by dots. (B) Model of in situ neural isolation (extrinsic denervation plus disruption of intrinsic neural continuity). Shaded area represents neurally isolated segment, with sites of intestinal transection and reanastomosis. Transmural biopsy specimens were again taken at 2, 6, and 12 weeks. and reanastomosing the distal duodenum and terminal ileum, thereby disrupting enteric neural continuity to the jejunoileum and any extrinsic nerves travelling in the wall of the gut from the duodenum and from the colon. We believe this to be an excellent model of complete neural isolation of the entire jejunoileum; we have shown previously that tissue catecholamine concentrations are reduced to almost unmeasureable values after this procedure. ${ }^{7}$ Although it is possible that some extrinsic innervation to the jejunoileum may remain within the wall of the superior mesenteric artery or vein, significant innervation is unlikely.

Dogs underwent repeat celiotomy at two, six, and 12 weeks after the initial neural isolation procedure. Fasting plasma samples were again collected before the animals were anesthetised, and were stored at $-20^{\circ} \mathrm{C}$ for later analysis. Biopsy specimens were obtained from the same region of the gut, but at least $5 \mathrm{~cm}$ away from previous biopsy sites. This was not always possible in the stomach, in which case anterior and posterior sites of corpus and antrum were alternated. Dogs were given routine maintenance care between biopsy sessions.

\section{TISSUE EXTRACTION AND RADIOIMMUNOASSAY}

Biopsy tisues were weighed and brought to a concentration of $0.05 \mathrm{~g}$ tissue $/ \mathrm{ml}$ (1:20, weight: volume) with $0 \cdot 1 \mathrm{~N} \mathrm{HCl}$. The tissue acid mixture was boiled for 10 minutes, homogenised (Brinkmann Polytron) and centrifuged at $3000 \mathrm{rpm}$ for 30 minutes at $4^{\circ} \mathrm{C}$. The supernatants were decanted and frozen at $-20^{\circ} \mathrm{C}$ until assayed. Concentrations of vasoactive intestinal peptide, substance $P$, and neuropeptide $Y$ in neutralised extracted supernatants (ng/g wet weight) and plasma samples $(\mathrm{pg} / \mathrm{ml})$ were determined by well established radioimmunoassay (RIA) methods. ${ }^{90}$ Tissue extracts and plasma samples from all timepoints were assayed together as a single set to minimise the effects of interassay variability (10-12\%). All samples were assayed in duplicate.

\section{HIGH PERFORMANCE LIQUID CHROMATOGRAPHY} (HPLC)

Immunoreactive species were characterised by HPLC. ${ }^{910}$ Extracts of tissues obtained before and after in vivo neural isolation were injected on a $\mathrm{C}_{18}$ reverse phase column (Rainin Short One with LKB model 2150 pumps and 2152 controller). The column was eluted with $\mathrm{CH}_{3} \mathrm{CN}$ (acetonitrile) in $0.1 \mathrm{~mol} / \mathrm{l}$ sodium acetate buffer $(\mathrm{pH} 4.0)$ at a rate of $0.5 \mathrm{ml} /$ minute. Acetonitrile gradients (LKB model 2040 gradient mixing assembly) were selected to ensure optimal separation for each neuropeptide as follows: vasoactive intestinal peptide at $10-60 \%$, substance $\mathrm{P}$ at $10-60 \%$, and neuropeptide $\mathrm{Y}$ at 30 $50 \%$. One minute fractions were collected, lyophilised (Savant Speed Vac Concentrator), reconstituted in respective assay buffers, and concentrations of vasoactive intestinal peptide, substance $P$, and neuropeptide $Y$ in each fraction were determined by RIA. Authentic standards for each neuropeptide were used to independently calibrate the system.

\section{ANALYSIS OF DATA}

With each dog serving as its own control, data from later sampling times were paired in respect of baseline data. Thus, the peptide concentrations at subsequent sampling points - that is two, six, and 12 weeks - were expressed in terms of changes in respect of control concentrations $(0$ weeks) for individual dogs. The resulting differences (deltas) for any given region were analysed by Student's $t$ test for paired data against a null hypothesis that the mean deltas for the respective timepoints equaled zero. Normality of distribution and equality of group variance were tested with the Wilk-Shapiro test and F test, respectively. Probability values were adjusted for multiple comparisons with a Bonferonni correction. All values are expressed as mean (SEM).

\section{Results}

GENERAL HEALTH OF ANIMALS

All dogs developed a profuse, watery diarrhoea that began about two days after neural isolation of the jejunoileum. Although the diarrhoea became less watery with time, it persisted until the end of the 12 week study. Despite a total body weight loss of 22 (4) \% in dogs surviving beyond one month postoperatively, the animals seemed healthy and had good appetites. The small intestine looked grossly normal at each of the subsequent operative procedures to obtain biopsy specimens, although there was obvious lymph node enlargement in the mesentery at two weeks. Three dogs died during the course of the study. Necropsy showed the following causes of death: faecal peritonitis secondary to leakage at the proximal colonic biopsy suture line (at one week); anaesthetic death (at two weeks); and 

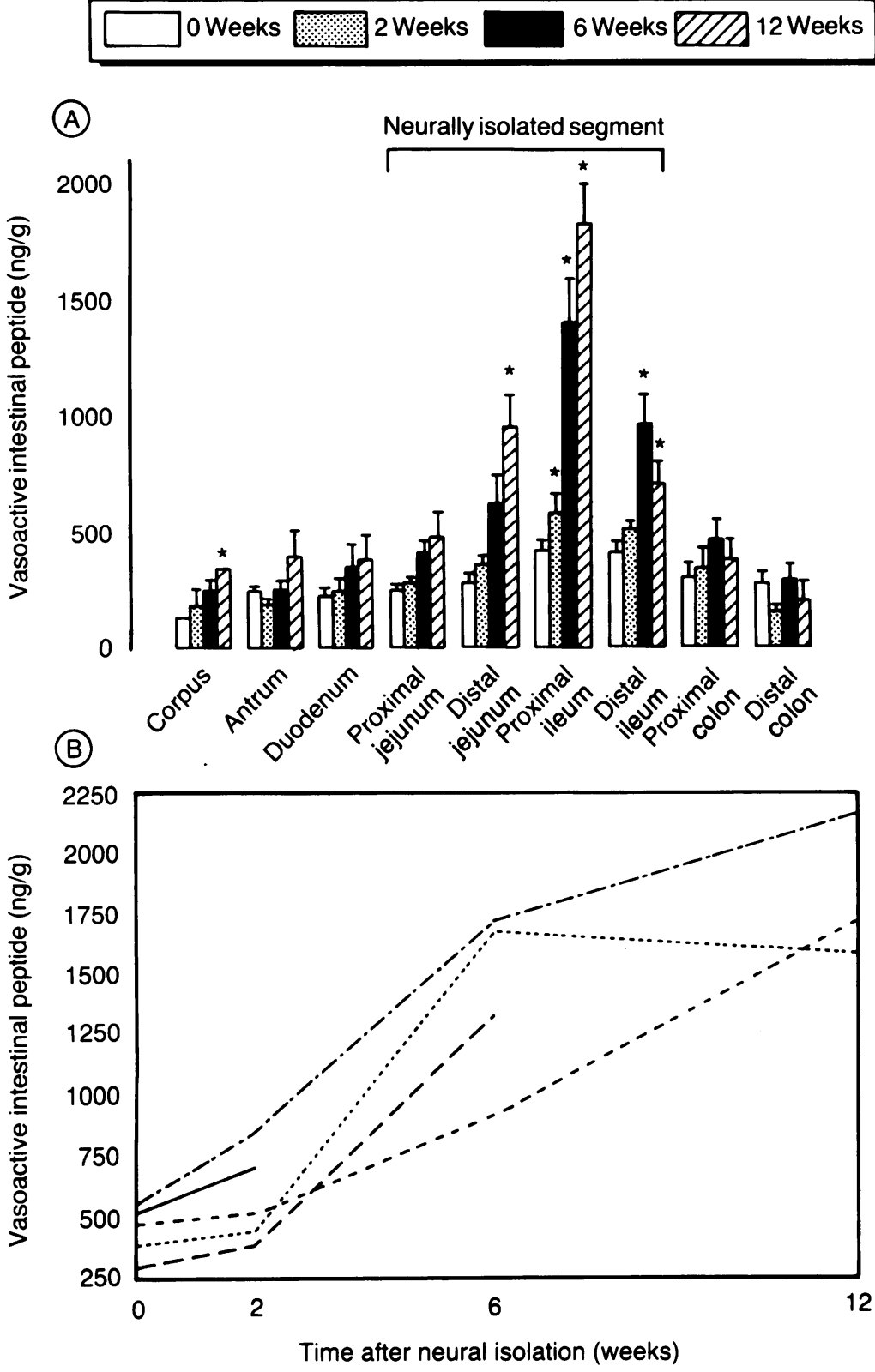

Figure 2: (A) Changes over time in gut tissue concentrations (mean (SEM)) of vasoactive intestinal peptide in a model of jejunoileal neural isolation. ${ }^{\star}$ Significantly different from 0 weeks; $p<0.05$. (B) Changes in individual dogs are shown for proximal ileum.

unexplained failure to thrive with acute emesis and bloody stool but no obvious intestinal obstruction, infarction, or site of haemorrhage (at seven weeks). Thus, there was one less dog at each sampling point so that there were six, five,

TABLE I Concentrations of neuropeptides in transmural specimens from the neurally intact dog gut. (Mean (SEM))

\begin{tabular}{llll}
\hline & \multicolumn{4}{l}{ Concentration $(n g / g$ tissue $)$} \\
\cline { 2 - 4 } Site & VIP & $S P$ & NPY \\
\hline Proximal gastric corpus & $130(28)$ & $1 \cdot 0(0 \cdot 1)$ & $45(16)$ \\
Gastric antrum & $246(23)$ & $2 \cdot 3(0 \cdot 6)$ & $60(15)$ \\
Duodenum & $227(36)$ & $5 \cdot 6(0 \cdot 9)$ & $13(3)$ \\
Proximal jejunum & $252(27)$ & $6 \cdot 1(1 \cdot 1)$ & $31(2)$ \\
Distal jejunum & $285(42)$ & $5 \cdot 0(0 \cdot 8)$ & $26(2)$ \\
Proximal ileum & $425(46)$ & $5 \cdot 7(1 \cdot 4)$ & $21(2)$ \\
Distal ileum & $417(49)$ & $3 \cdot 8(0 \cdot 5)$ & $17(3)$ \\
Proximal colon & $306(66)$ & $3 \cdot 4(0 \cdot 6)$ & $24(6)$ \\
Distal colon & $280(50)$ & $3 \cdot 7(0 \cdot 5)$ & $24(5)$ \\
\hline
\end{tabular}

VIP= vasoactive intestinal peptide; $S P=$ substance $P$; NPY = neuropeptide Y.
TABLE II Concentrations of neuropeptides in plasma $(\mathrm{pg} / \mathrm{ml})$ after a canine model of neural isolation of the jejunoileum

\begin{tabular}{|c|c|c|c|c|}
\hline \multirow[b]{2}{*}{ Peptide } & \multicolumn{4}{|c|}{ Time after neural isolation } \\
\hline & $\begin{array}{l}0 \text { Weeks } \\
(n=6)\end{array}$ & $\begin{array}{l}2 \text { Weeks } \\
(n=5)\end{array}$ & $\begin{array}{l}6 \text { Weeks } \\
(n=4)\end{array}$ & $\begin{array}{l}12 \text { Weeks } \\
(n=3)\end{array}$ \\
\hline $\begin{array}{l}\text { VIP } \\
\text { SP } \\
\text { NPY }\end{array}$ & $\begin{array}{c}30(4) \\
9 \cdot 3(0 \cdot 5) \\
3320(480)\end{array}$ & $\begin{array}{c}38(7) \\
14 \cdot 6(1 \cdot 0) \dagger \\
1560(230) \dagger\end{array}$ & $\begin{array}{c}24(2) \\
10 \cdot 8(0 \cdot 6) \\
1400(390) t\end{array}$ & $\begin{array}{c}31(9) \\
10 \cdot 7(0 \cdot 7) \\
1410(80)\end{array}$ \\
\hline
\end{tabular}

$\star$ Neurally intact gut. $\nmid \mathrm{p}<0.05 v 0$ weeks (baseline)

$\mathrm{VIP}=$ vascoactive intestinal peptide $; \mathrm{SP}=$ substance $\mathrm{P}$

NPY = neuropeptide $\mathrm{Y}$.

four, and three dogs at baseline, two, six, and 12 weeks respectively.

\section{NEUROPEPTIDE CONCENTRATIONS}

Results of RIAs for vasoactive intestinal peptide, substance $\mathrm{P}$, and neuropeptide $\mathrm{Y}$ in plasma (pg/ $\mathrm{ml}$ ) and gastrointestinal tissues (ng/g) are presented in Tables I and II and Figures 2 to 4. Marked changes were seen in the tissue concentrations of all neuropeptides examined and in the fasting plasma concentrations of neuropeptide $\mathrm{Y}$.

Vasoactive intestinal peptide and substance $P$

Baseline tissue concentrations of vasoactive intestinal peptide and substance $P$ (Table I) in the neurally intact gut - that is, before neural isolation - followed the distributional pattern we and others have reported previously. ${ }^{112}$ Concentrations of vasoactive intestinal peptide ranged from $130(28) \mathrm{ng} / \mathrm{g}$ in the proximal corpus to 425 (46) $\mathrm{ng} / \mathrm{g}$ in the proximal ileum. Baseline concentations of substance $P$ ranged from (SEM) 1.0 $(0 \cdot 1) \mathrm{ng} / \mathrm{g}$ in the proximal corpus to $6 \cdot 1(1 \cdot 1) \mathrm{ng} / \mathrm{g}$ in the proximal jejunum. After neural isolation, tissue concentrations of vasoactive intestinal peptide and substance $P$ (Figs 2 and 3 ) increased progressively over the course of the 12 week postoperative period (198\% and $217 \%$ average maximal increases across neurally isolated regions, respectively). Surprisingly, there were also increases of a lesser magnitude in some gastric, duodenal, and colonic regions outside the neurally isolated segment. Vasoactive intestinal peptide in fasting plasma did not change, while substance $P$ was increased at two weeks but returned to baseline at later time-points (Table II).

\section{Neuropeptide $Y$}

In contrast to vasoactive intestinal peptide and substance $\mathrm{P}$, concentrations of neuropeptide $\mathrm{Y}$ decreased in the jejunoileum after neural isolation. Baseline concentrations in the neurally intact gut (Table I) were lowest in the duodenum (13 (3) $\mathrm{ng} / \mathrm{g}$ ) and greatest in the gastric antrum $(60(15) \mathrm{ng} / \mathrm{g})$, with intermediate concentrations (17-31 ng/g) across the regions distal to the duodenum. After neural isolation, tissue concentrations of neuropeptide $\mathrm{Y}$ in the jejunoileum were decreased $(30-70 \%)$ two weeks after operation and remained decreased throughout the 12 week study period (Fig 4). Fasting plasma concentrations of neuropeptide $\mathrm{Y}$ were also 

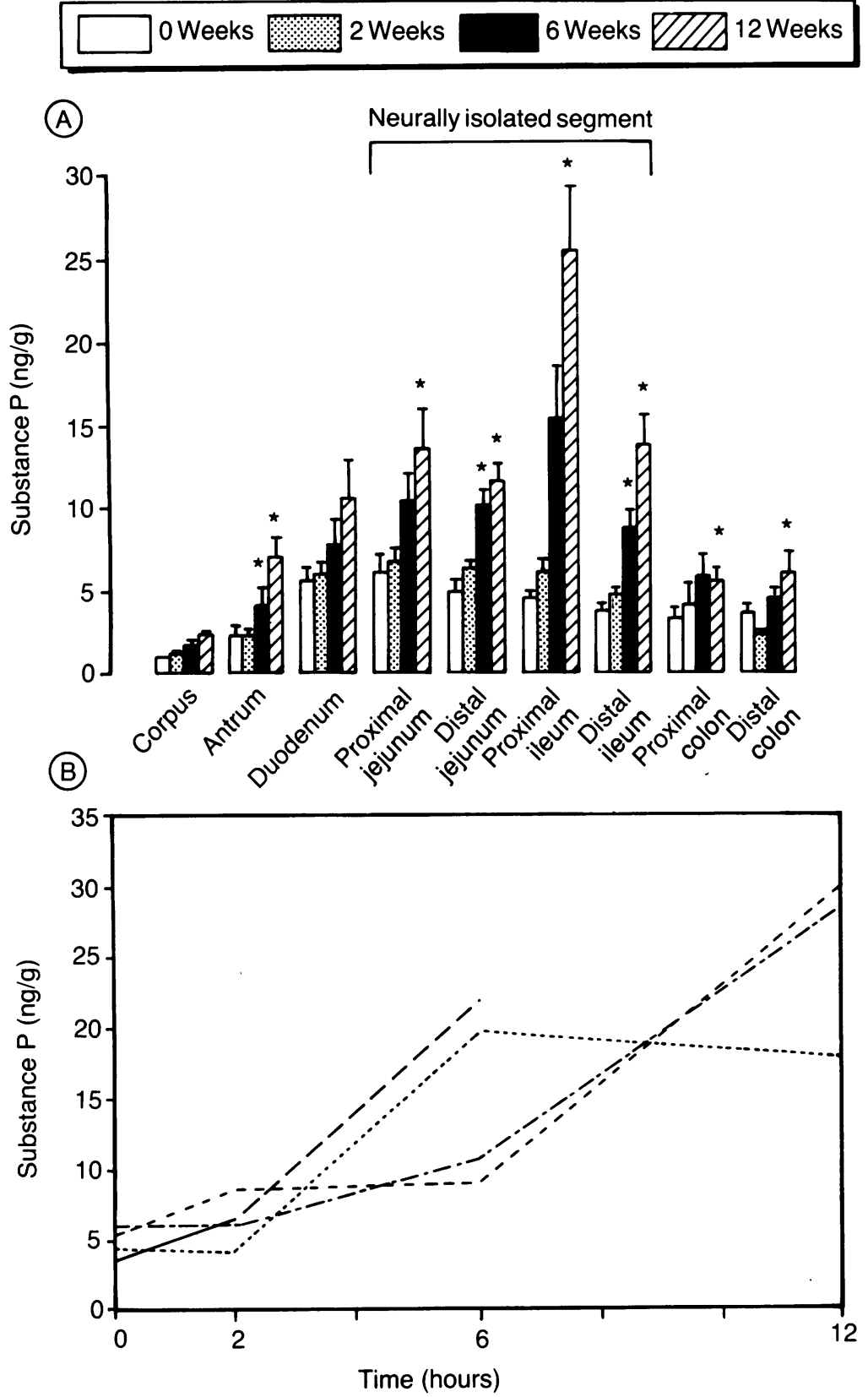

Figure 3: (A) Changes over time in gut tissue concentrations (mean (SEM)) of substance $P$ in a

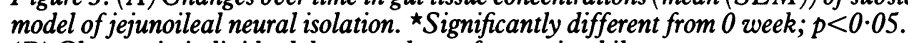

(B) Changes in individual dogs are shown for proximal ileum.

decreased at two weeks and remained decreased thereafter (Table II).

\section{HPLC characterisation}

Major immunoreactive species of vasoactive intestinal peptide, substance $P$, and neuropeptide $\mathrm{Y}$ in biopsy extracts coeluted as single peaks with their respective authentic standards, as shown by $\mathrm{C}_{18}$ reverse phase HPLC (Fig 5). These elution profiles were not changed after neural isolation.

\section{Discussion}

Enteric concentrations of neuropeptides are altered in this canine model of in situ neural isolation of the entire jejunoileum, which involves both extrinsic denervation (vagotomy, sympathectomy) and disruption of intrinsic (enteric) neural continuity. RIA of transmural biopsy extracts indicated that vasoactive intestinal peptide and substance $P$ were increased, while neuropeptide $\mathrm{Y}$ was decreased in both tissues and plasma. Moreover, changes in vasoactive intestinal peptide and substance $P$ occurred in a temporal manner, with progressively more pronounced alterations evident at successive timepoints after initial surgery.

Earlier studies have investigated the effects of selective pharmacological and surgical denervations on the neuropeptidergic innervation of the gut. We showed that chemical sympathectomy, induced in rats by guanethidine, increased enteric tissue concentrations of vasoactive intestinal peptide and neurotensin ${ }^{1314}$ while decreasing norepinephrine and, to a lesser extent, neuropeptide $Y .{ }^{15}$ Surgical sympathectomy or extrinsic denervation of the intestine of mouse, ${ }^{16}$ rat, ${ }^{16}$ guinea pig, $,^{17}, \mathrm{dog},{ }^{18}$ and pig $^{19}$ seemed to leave intrinsic peptidergic nerves, including those staining for vasoactive intestinal peptide, substance $P$, neuropeptide $Y$, cholecystokinin, somatostatin, and enkephalin largely unaffected. With one exception, ${ }^{19}$ these earlier studies looked for relatively acute changes (less than three weeks). Our data indicate that a longer period of observation (a minimum of six weeks) may be necessary for significant alterations to become evident. Moreover, these studies relied to a great extent on semiquantitative immunocytochemical techniques, and may therefore have overlooked changes less evident by these methods. ${ }^{2021}$ Our observations would be complemented by histochemical localisation studies to help determine the relative contribution of mucosal-submucosal and muscularis layers to the changes seen in whole thickness biopsy specimens, and these studies are underway.

Other investigators have examined the changes in the neuropeptidergic innervation of transplated small bowel, another model of complete neural isolation. Progressive reductions in neurocrine peptides have occurred in rat intestinal allografts which seemed to correlate with rejection phenomena ${ }^{2223}$ and associated mucosal atrophy. ${ }^{24}$ Gebhardt et $a l^{25}$ found no change in the immunohistochemical distribution or content of vasoactive intestinal peptide and cholecystokinin after intestinal transplantation in the rat. Recently, Bass $e t a l^{26}$ reported that the vasoactive intestinal peptide content (determined by RIA) and vasoactive intestinal peptide receptors (determined by autoradiography) were preserved largely unaltered in their model of intestinal transplantation. Direct comparisons with our study is difficult insofar as Bass et $a l^{26}$ used a rat model of heterotopic subcutaneous transplantation of fetal gut and did not examine the graft beyond three weeks postoperatively. The authors noted the discrepancy between their findings and our preliminary report, ${ }^{27}$ but concluded that both studies suggest that enteric nerves and their peptide neurotransmitters are not destroyed by transplantation or extrinsic denervation.

Extrinsic nerves, both sympathetic and parasympathetic, modulate many aspects of function of the upper gut. Proabsorptive effects have been 


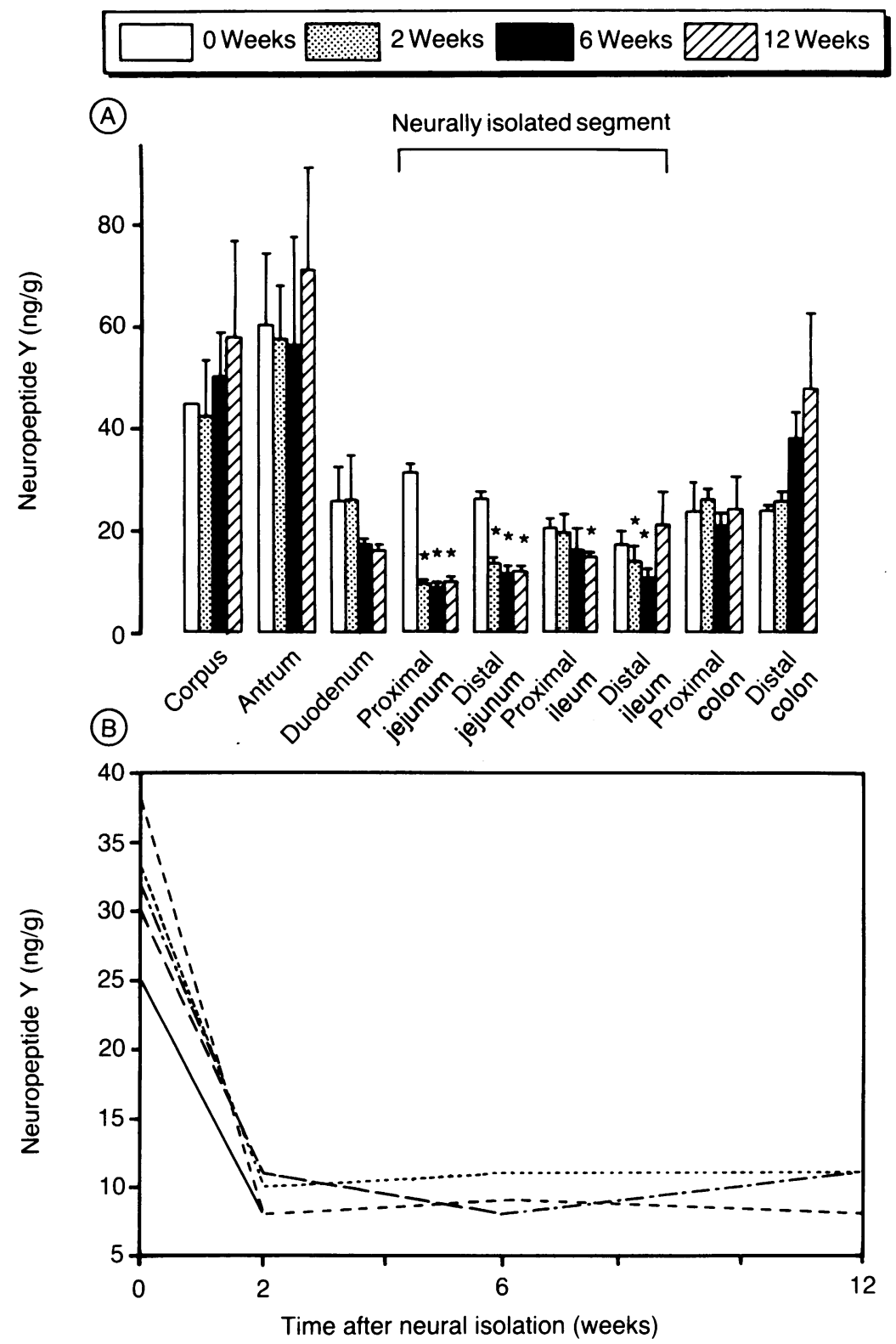

Figure 4: (A) Changes over time (mean (SEM)) in gut tissue concentrations of neuropeptide $Y$ in a model of jejunoileal neural isolation. ${ }^{\star}$ Significantly different from 0 weeks; $p<0 \cdot 05$. (B) Changes in individual dogs are shown for proximal jejunum.

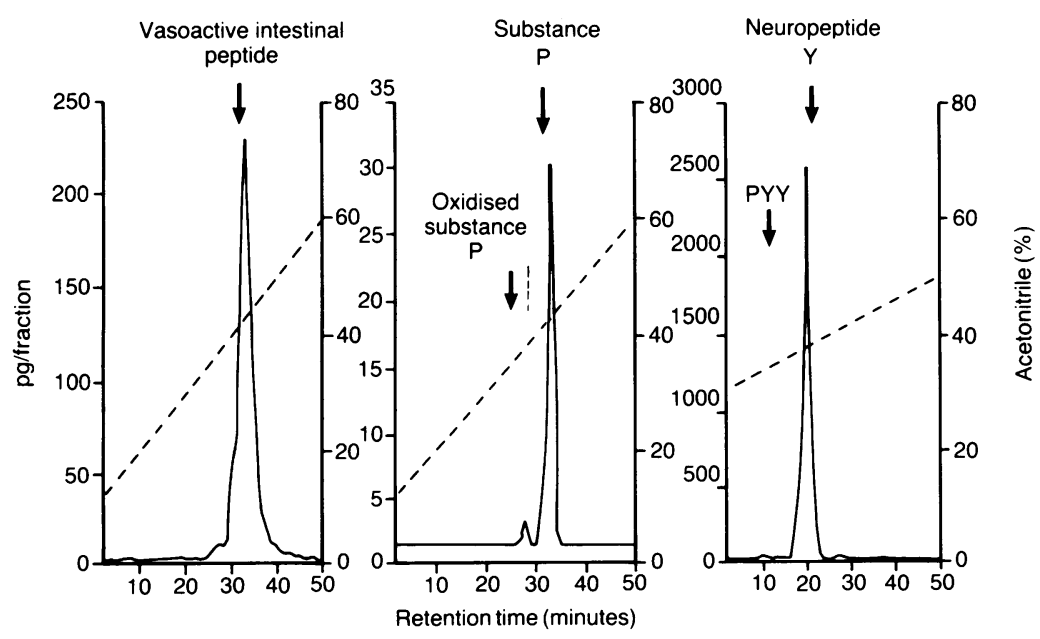

Figure 5: $C_{18}$ reverse phase high performance liquid chromatography separation of extracts of transmural biopsy specimens of small bowel taken before surgical neural isolation of the jejunoiluem. Radioimmunoassays for vasoactive intestinal peptide $(V I P)$, substance $P(S P)$ and neuropeptide $Y(N P Y)$ each identified one major immunoreactive species which coeluted with authentic standard (arrows). Elution positions for oxidized SP and peptide $Y Y(P Y Y)$ are also shown, as are acetonitrile gradients employed. These elution profiles did not change after neural isolation. observed after infusion of adrenergic sympathomimetics $^{2829}$ or neuropeptide $\mathrm{Y},{ }^{60}$ which colocalises with norepinephrine in sympathetic nerves to the gut. ${ }^{1-3}$ In contrast, vasoactive intestinal peptide and substance $P$ induce a prosecretory effect in the small bowel,,$^{560-32}$ and vasoactive intestinal peptide has been implicated in the pathogenesis of the watery diarrhoea, hypokalaemia, achlorhydria (WDHA) syndrome. ${ }^{3133}$ Clearly, significant changes in the content or release, of these agents might affect mucosal transport. ${ }^{6}$ An increase in the secretagogues vasoactive intestinal peptide and substance $\mathrm{P}$ and/or a decrease in the proabsorptive agents neuropeptide $\mathrm{Y}$ and norepinephrine could contribute to the profuse watery diarrhoea we observed in this model. Similarly, vasoactive intestinal peptide, substance $P$, and neuropeptide $\mathrm{Y}$ modulate smooth muscle contractility, ${ }^{45} 34$ and alterations in tissue concentrations or release of these peptides could underlie some of the changes in motility in the model we have reported previously. ${ }^{78}{ }^{35} \mathrm{~A}$ final aspect deserving comment is the role of certain peptides in modulating the gastrointestinal neuroimmune axis. We and others have shown that vasoactive intestinal peptide exerts potent immunosuppressive actions via $\mathrm{T}$ cell specific mechanisms, ${ }^{36-38}$ and that sympathectomy induces concomitant changes in vasoactive intestinal peptide concentrations and gut immune response. ${ }^{14}$ Understanding the neuroimmunomodulatory properties of vasoactive intestinal peptide and other gut peptides may provide major insights for transplantation surgery.

Our study also showed that neuropeptide concentrations seemed to be affected, albeit to a lesser extent, in gut regions outside the neurally isolated segment. Possible explanations include the prospect of partial extrinsic denervation of duodenum or colon by sectioning of nerves with widespread collateral projections, ${ }^{39}$ the effects of blood borne trophic factors, ${ }^{4041}$ or mechanisms working via the intrinsic plexuses, which are disrupted in this model. Furness, Costa et $a l^{41842}$ have shown that neural processes which traverse the bowel wall in both orad and anal directions regrow across the anastomosis of transected intestine by times corresponding to the later points in our study. Re-establishment of these neural projections may have altered the enteric neural milieu in neighboring regions outside the denervated segment.

In summary, alterations in neuropeptidergic innervation of the neurally isolated jejunoileum suggest an adaptive response of potential importance in the function of the denervated small bowel that may have important implications for intestinal transplantation. $\mathrm{We}^{7835}$ and others ${ }^{43}$ have reported alterations of absorptive and motor function in the denervated or transplanted gut. The adaptive responses of the denervated or transplanted bowel, and ultimately its functional capacity, will reflect a complex interplay of luminal, neural, and humoral factors. The neuroeffector agents of the enteric nervous system are likely to be among the final mediators of this response and the present study indicates that important longterm changes may occur in this system. 
The authors are indebted to K T Nguyen, J E Bailey, B L Caron, S M Kuntz, S R Michener, D R Roddy, and J B Worra for technical assistance, to A R Zinsmeister for statistical consultation, and to D I Frank for preparation of the manuscript.

Supported in part by USPHS NIH Grants DK39337 (RO1 Supported in part by USPHS NIH Grants DK 39337 (RO1
Award-MGS) and DK34988 (Digestive Diseases Core Center), Award-MGS) and DK 34988
and the Mayo Foundation.

and the Mayo Foundation.
Portions of this work were presented at the Annual Meeting of Portions of this work were presented at the Annual Meeting of
the American Gastroenterological Association on 18 May, 1988, in New Orleans, and published in abstract form (Gastroenterology 1988; 94: A323).

1 Furness JB, Morris JL, Gibbons IL, Costa M. Chemical coding of neurons and plurichemical transmission. Ann Rev Pharmacol Toxicol 1989; 29: 289-306.

2 Bartfai T, Iverfeldt K, Fisone G, Serfozo P. Regulation of the release of coexisting neurotransmitters. Ann Rev Pharmacol Toxicol 1988; 28: 285-310.

3 Lundberg JM, Hokfelt T. Multiple co-existence of peptides and classical transmitters in peripheral autonomic and sensory neurons - functional and pharmacological implications. Prog Brain Res 1986; 68: 241-62

4 Furness JB, Costa M, Franco R, Llewellyn-Smith IJ. Neuronal peptides in the intestine: distribution and possible functions. Adv Biochem Psychopharmacol 1980; 22: 601-17.

5 Dockray GJ. Physiology of enteric neuropeptides. In: Johnson LR, ed. Physiology of the gastrointestinal tract. New York: Raven Press, 1987: 41-66.

6 Cooke HJ. Neurobiology of the intestinal mucosa. Gastroenterology 1986; 90: 1057-81.

7 Sarr MG, Duenes JA, Tanaka M. Jejunoileal autotransplantation: effects on small intestinal motility. Surg Forum 1987; 38: $160-2$.

8 Sarr MG, Duenes JA, Tanaka $M$. A model of jejunoileal in vivo neural isolation of the entire jejunoileum: transplantation and the effects on intestinal motility. $\mathcal{F}$ Surg Res 1989; 47: 266-72.

9 Yaksh TL, Michener SR, Bailey JE, Harty GJ, Lucas DL, Nelson DK, et al. Survey of distributions of substance P, vasoactive intestinal polypeptide, cholecystokinin, neurotensin, met-enkephalin, bombesin, and PHI in the spinal chord of cat, dog, sloth and monkey. Peptides 1988; 9: 35772 .

10 Koch TR, Roddy DR, Carney JA, Telander RL, Go VLW. Distribution, quantitation and origin of immunoreactive
neuropeptide $\mathrm{Y}$ in the human gastrointestinal tract. Regul neuropeptide Y in the
Pep 1988; 21: 309-19.

11 Go VLW, Koch TR. Distribution of gut peptides. In: Makhlouf GM, ed. Handbook of physiology. Vol II. Section 6: neuroendocrinology of the gut. Washington DC American Physiology Society, 1989: 111-22.

12 Schultzberg M, Hokfelt T, Nilsson G, Terenius L, Rehfeld $\mathrm{JF}$, Brown M, et al. Distribution of peptide and catecholamine-containing neurons in the gastrointestinal tract of rat and guinea pig: immunohistochemical studies with antisera to substance $P$, vasoactive intestinal polypepwith antisera to substance $P$, vasoactive intestinal polypep-
tide, enkephalins, somatostatin, gastrin/cholecystokinin, tide, enkephalins, somatostatin, gastrin/cholecystokinin, neurotesin, and

13 Nelson DK, Service JE, Studelska DR, Brimijoin S, Go VLW. Gastrointestinal neuropeptide concentrations following guanethidine sympathectomy. $\mathcal{F}$ Auton Nerv Syst 1988; 22: 203-10.

14 Nelson DK, Nguyen TT, Krco CJ, Tyce GM, Go VLW. The gastrointestinal neuroimmune axis: developmental differentiation in a model of peripheral adrenergic neuropathy. Gastroenterology 1990; 98:A514.

15 Nelson DK, Roddy DR, Tyce GM, Brimijoin S, Go VLW. Differential effect of guanethidine sympathectomy on norepinephrine (NE) dopamine (DA) and neuropeptide Y (NPY) in the gut: evidence of non-sympathetic stores of (NPY) in the gut: evidence of non-sympathetic

16 Ekblad E, Ekelund M, Graffner H, Hakanson R, Sundler F. Peptide-containing nerve fibers in the stomach wall of rat and mouse. Gastroenterology 1985; 89: 73-85.

17 Keast JR, Furness JB, Costa M. Origins of peptide and norepinephrine nerves in the mucosa of the guinea pig smal intestine. Gastroenterology 1084; 86: 637-44.

18 Daniel EE, Furness JB, Costa M, Belbeck L. The projections of chemically identified nerve fibers in canine ileum. Cell Tissue Res 1987; 247: 377-84

19 Malmfors G, Leander S, Brodin E, Hakanson R, Holmin T,
Sundler F. Peptide-containing neurons intrinsic to the gut wall. Cell Tissue Res 1981; 214: 225-38.

20 Koch TR, Carney JA, Go VLW. Distribution and quantification of gut neuropeptides in normal intestine and inflammatory bowel diseases. Dig Dis Sci 1987; 32: 369-76.

21 Dahl JL, Bloom DD, Epstein ML, Fox DA, Bass P. Effect of chemical ablation of myenteric neurons on neurotransmitter chemical ablation of myenteric neurons on neurotransmitter

22 Teitelbaum DH, Dunaway DJ, Wise WE, Cooke HJ, Sonnino $\mathrm{RE}$, Stellin G, et al. Loss of intestinal integrity as a maker of small bowel transplant rejection. Gastroenterology 1988; 94: A457.

23 Teitelbaum DH, O'Dorisio TM, Qualman SJ, Sonnino RE, Dunaway DJ, Harmel RP Jr. Alteration in gastrointestina peptide tissue levels in rejecting small bowel transplants. Gastroenterology 1988; 94: A57.

24 Deltz E, Gebhardt JH, Preissner Ch, Schroeder P, Hansmann ML, Kaiserling E, et al. Distribution of gastrointestinal hormones in the adaptive response after small bowel transplantation. Gut 1987; 28 (suppl): 217-20

25 Gebhardt JH, Preissner WCh, Deltz E, Kaiserling E, MullerHermelink HK. Patterns of gastrointestinal hormone distribution after small bowel transplantation. In: Deltz E, Thiede A, Hamelmann H, eds. Small bowel transplantation: experimental and clinical fundamentals. Berlin: SpringerVerlag, 1986: 84-6.

26 Bass BL, Sayadi H, Harmon JW, Wall S, Korman LY. VIP receptors and content after small bowel transplantation. F Surg Res 1989; 46: 431-8.

27 Nelson DK, Sarr MG, Bailey JE, Michener SR, Nguyen K, Roddy DR, et al. Intestinal transplantation: effect on gut neuropeptides. Gastroenterology 1988; 94: A 323.

28 Chang EB, Field F, Miller RJ. $\alpha_{2}$ adrenergic receptor regulation of ion transport in rabbit ileum. Am $\mathcal{F}$ Physiol 1982; 242: G237-42.

29 Greenwood B, Tremblay L, Davison JS. Sympathetic control of motility, fluid transport, and transmural potential difference in the rabbit ileum. Am F Physiol 1987; 253: G726-9.

30 McCulloch CR, Kuwahara A, Condon CD, Cooke HJ. Neuropeptide modification of chloride secretion in guinea pig distal colon. Regul Pep 1987; 19: 35-43.

31 Calam J, Yiangov Y, Nikou GC, Chrysanthou BJ, Beacham JL, Bloom SR. Effect of preprovasoactive intestinal polypeptide-derived peptides on ileal output. Gastropolypeptide-derived peptide
enterology $1990 ; 98: 505-8$.

32 Kachur JF, Miller RJ, Field M, Rivier J. Neurohumoral control of ileal electrolyte transport: II. Neurotensin and control of ileal electrolyte transport: I1. Neurotensin

33 Bloom SR, Polak JM, Pearse AGE. Vasoactive intestinal peptide and watery-diarrhoea syndrome. Lancet 1973; ii: $14-6$.

34 Fox JET, Daniel EE. Substance P. A potent inhibitor of the canine small intestine in vivo. Am $\mathcal{F}$ Physiol 1986; 250: G21-7.

35 Sarr MG, Kelly KA. Myoelectric activity of the autotransplanted canine jejunoileum. Gastroenterology 1981; 81: 30310.

36 Nguyen TT, Krco CJ, Gores A, Go VLW. Analysis of the immunomodulatory properties of the secretin-glucagon family of peptides on mouse lymphoid cell functions and the family of peptides on mouse lymphoid cell functions and the demonstration of specific

37 O'Dorisio MS, Wood CL, O'Dorisio TM. Vasoactive intestinal peptide and neuropeptide modulation of the immune response. F Immunol 1985; 135: 792-6.

38 Ottaway CA. Selective effects of vasoactive intestinal peptide on the mitogenic response of murine $\mathrm{T}$ cells. Immunology 1987; 62: 291-7.

39 Janig W. Spinal cord integration of colon function: afferent and efferent pathways. Dig Dis Sci 1989; 34: 979.

40 Dalsgaard CJ, Hultgardh-Nilsson A, Haegerstrand A, Nilsson J. Neuropeptides as growth factors. Possible roles in human diseases. Regul Pept 1989; 25: 1-9.

41 Enochs MR, Johnson LR. Trophic effects of gastrointestinal hormones: physiological implications. Fed Proc 1977; 36: 1942-7.

42 Galligan JJ, Furness JB, Costa M. Migration of the myointerruption of the myenteric plexus: intestinal transection and regeneration of enteric nerves in the guinea pig. Gastroenterology 1989; 97: 1135-46.

43 Watson AJM, Lear PA, Montgomery A, Elliott E, Dacre J, Farthing MJG, et al. Water, electrolyte, glucose, and glycine absorption in rat small intestine transplants. Gastroenterology 1988; 94: 863-9. 